\title{
Biologically and Mechanically Biocompatible Titanium Alloys
}

\author{
Mitsuo Niinomi \\ Department of Biomaterials Science, Institute for Materials Research, Tohoku University, Sendai 980-8577, Japan
}

$\mathrm{Nb}$, Ta, and $\mathrm{Zr}$ are the favorable nontoxic and allergy-free alloying elements suitable for use in titanium alloys for biomedical applications. Low-rigidity titanium alloys composed of nontoxic and allergy-free elements are receiving considerable attention. The advantage of low-rigidity titanium alloys in the healing of bone fracture and bone remodeling is successfully proven by using tibia of rabbit as a fracture model. Ni-free superelastic and shape memory titanium alloys for biomedical applications are being actively developed. The mechanical properties such as fatigue and fretting fatigue are important from the viewpoint of mechanical properties, which may be collectively referred to as mechanical biocompatibilities in the broad sense, in addition to the rigidity, i.e. Young's modulus. Bioactive surface modifications of titanium alloys for biomedical applications are very important for achieving further biocompatibility. [doi:10.2320/matertrans.L-MRA2008828]

(Received March 26, 2008; Accepted April 14, 2008; Published September 25, 2008)

Keywords: titanium alloy, biomedical application, dental application, biological biocompatibility, mechanical biocompatibility

\section{Introduction}

Metallic biomaterials such as stainless steels, Co-Cr alloys, and titanium and its alloys are currently utilized as structural materials in artificial hip joints, bone plates and screws, and artificial dental roots; they are mainly used in implants that replace hard tissue. Some metallic biomaterials (biometals) known as stents are also used for reconstructing blood vessels. Among biometals, titanium alloys have high biocompatibility, specific strength, and corrosion resistance, and exhibit the most suitable characteristics for biomedical applications. Recently, the titanium alloys that are composed of nontoxic and allergy-free elements have been developed by taking their biological biocompatibility account into. ${ }^{1,2)}$ These alloys must also have high strength and a long fatigue life, that is, high fatigue strength. A low Young's modulus equivalent to that of the cortical bone is a simultaneously required in order to inhibit bone absorption. ${ }^{1,3-6)}$ Porous titanium and its alloys that have a low Young's modulus have also been developed. Titanium alloys for biomedical applications must have various functionalities such as superelasticity and shape memory characteristics. However, the mechanism of the superelastic behavior of some titanium alloys in biomedical applications is still unknown. ${ }^{7-9)}$ It has been observed that wear loss occurs, indifferent areas such as the area between the stem and the bone, and loosening may also occur in such cases. Further, there is a possibility fretting fatigue will occur in the contact area of two bodies, for example, between like the bone plate and the screw. Therefore, the wear and fretting fatigue characteristics of titanium alloy used in biomedical applications are also very important. The Young's modulus and tensile strength, ductility, fatigue life, fretting fatigue life, wear properties, functionalities, etc., should be controlled so that their levels are suitable for structural biomaterials used in implants that replace hard tissue. These factors may be collectively referred to as mechanical biocompatibilities in the broad sense. For the long term usage of metallic implants, mechanical biocompatibilities should be enhanced.

Research and development of bioactive ceramic surface modifications for improving the biocompatibility of titanium alloys is also increasing ${ }^{10)}$ because titanium alloys are classified as bioinert from the view point of the patterns of osteogenesis. ${ }^{11)}$

Further, biopolymer surface modifications are carried out on titanium alloys for achieving excellent blood compatibility. It is difficult to bond biopolymers to metallic biomaterials via chemical bonding. The first step in this task is to coat a polymer on the surface of titanium alloys, or to press the polymer into porous titanium alloys. At present, the challenging task of bonding blood-compatible polymers to titanium alloys via chemical bonding is being attempted. ${ }^{12)}$ If this surface modification of metallic biomaterials via chemical bonding is successfully performed, high-endurance long-life scaffolds for artificial organs may be developed for incorporation with tissue engineering.

In the future, new biomaterials and biomaterials science will be developed when the harmonization of titanium (metallic), ceramic, and polymer biomaterials via chemical bonding is satisfactorily achieved. Simultaneously, the harmonization of titanium (metallic)-ceramic-polymer biomaterials and living tissues will also be achieved.

Furthermore, the direct or indirect evaluation of biocompatibility using animals, ${ }^{13)}$ or cells, ${ }^{14,15)}$ and the evaluation of mechanical performance parameters ${ }^{16,17)}$ such as fatigue, fretting fatigue, and fracture toughness is also being actively undertaken.

Since new developments in titanium alloys for biomedical applications are taking place, the selected topics on research and development in biologically and mechanically biocompatible titanium alloys for biomedical applications will be described in this paper.

\section{Development of Titanium Alloys for Biomedical Applications}

\subsection{V-free $(\alpha+\beta)$-type titanium alloys composed of non-toxic elements}

V-free $(\alpha+\beta)$-type Ti-15Sn-4Nb-2Ta-0.2Pd and Ti-15Zr$4 \mathrm{Nb}-2 \mathrm{Ta}-0.2 \mathrm{Pd}^{18)}$ composed of nontoxic elements have been developed using the d-electron alloy design method. These alloys exhibit high fatigue strength. Attempts have been 


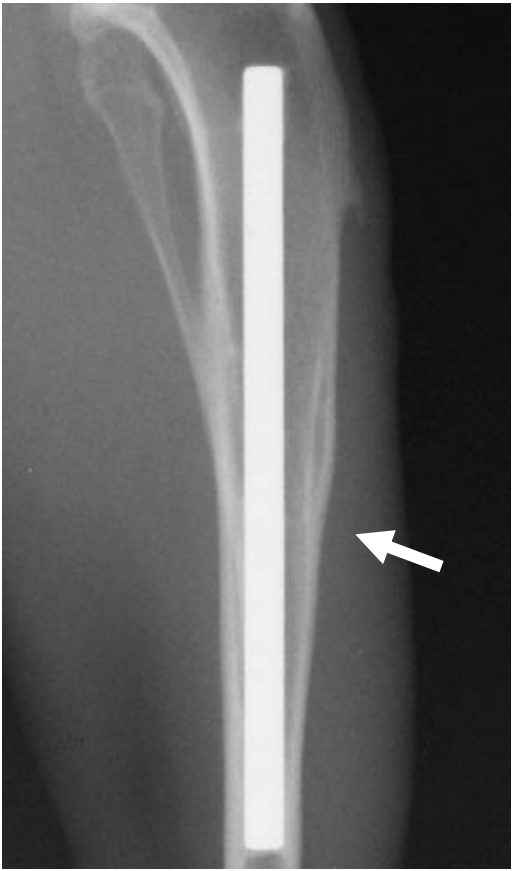

TNTZ

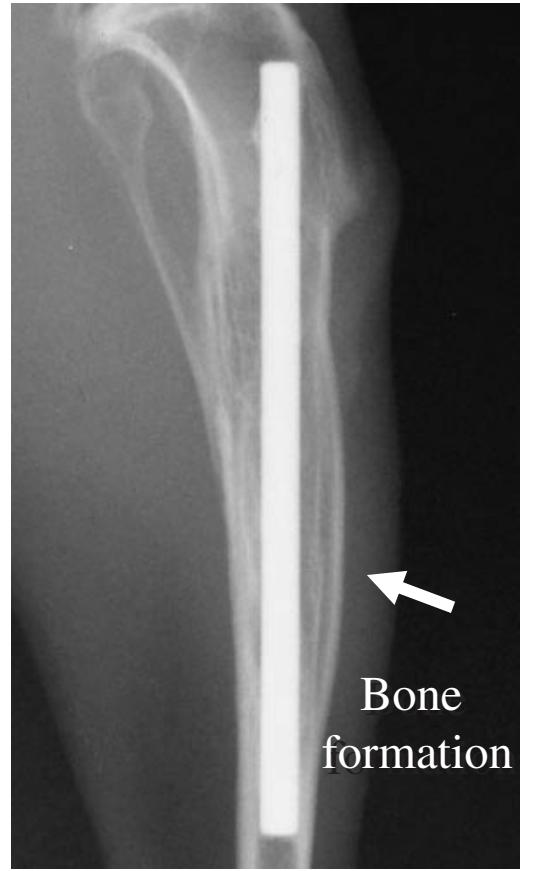

Ti-6Al-4V ELI

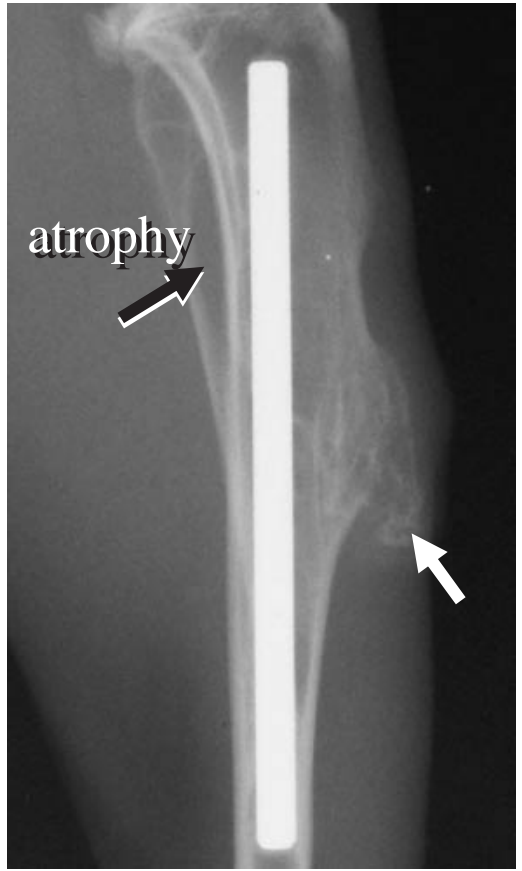

SUS316L

Fig. 1 X-ray photographs of tibia at 24 weeks after implantation.

made to apply these alloys in the fabrication of dental prostheses such as crowns and dentures by dental precision casting. ${ }^{10)}$

\subsection{Low-modulus $\beta$-type titanium alloys composed of nontoxic and allergy-free elements}

The developments in the manufacture of titanium alloys for biomedical applications have taken into account not only the safety of alloy's constituent elements for use in the human body but also their mechanical biocompatibility. With regard to the mechanical biocompatibility, Young's modulus is the major factor, and its value for the alloy should be equivalent to that of the cortical bone in order to inhibit the bone absorption. Further, $\beta$-type titanium alloys are receiving attention for biomedical applications because their Young's moduli are much less than those of $\alpha$ - and $(\alpha+\beta)$-type titanium alloys. The representative $\beta$-type titanium alloys developed for biomedical applications are listed in Table $1{ }^{19)}$ First, Ti-13Nb-13Zr was developed. The Young's modulus of $\mathrm{Ti}-13 \mathrm{Nb}-13 \mathrm{Zr}$ is reported to range from 44 through $88 \mathrm{GPa}$. Subsequently, Ti-12Mo-6Zr-2Fe, Ti-15Mo, Ti-16Nb-10Hf, Ti-15Mo-5Zr-3Al, Ti-15Mo-2.8Nb-0.2Si0.26 , etc., were developed. Among these, Ti-13Nb-13Zr, Ti-12Mo-6Zr-2Fe, and Ti-15Mo are registered in the ASTM standards while $\mathrm{Ti}-15 \mathrm{Mo}-5 \mathrm{Zr}-3 \mathrm{Al}$ is registered in JIS $\mathrm{T}$ 7401-6. Further, Ti-35Nb-7Zr-5Ta (referred to as TNZT) and Ti-29Nb-13Ta-4.6Zr (referred to as TNTZ) were developed. TNTZ exhibits not only a low Young's modulus but also superelastic behavior, as stated below. Subsequently, Ti-FeTa system alloy, Ti-Zr-Nb-Ta system alloy, Ti-Fe-Mo-Mn$\mathrm{Nb}-\mathrm{Zr}$ system alloy, Ti-Mo-Mn-Nb-Zr system alloy, etc., which exhibit low Young's moduli were developed. ${ }^{10)}$ The Young's modulus of $\mathrm{Ti}-\mathrm{Nb}-\mathrm{Sn}$, which received attention owing to its shape memory characteristics, is also small, and
Table 1 Selected low modulus $\beta$ type titanium alloys for biomedical applications.

\begin{tabular}{lcc}
\hline $\begin{array}{l}\text { Titanium and } \\
\text { its alloys }\end{array}$ & Standard & Type of Alloy \\
\hline Ti-13Nb-13Zr & ASTM F 1713 & $\beta$ \\
Ti-12Mo-6Zr-2Fe & ASTM F 1813 & $\beta$ \\
Ti-12Mo-5Zr-5Sn & - & $\beta$ \\
Ti-15Mo & ASTM F 2066 & $\beta$ \\
Ti-16Nb-10Hf & - & $\beta$ \\
Ti-15Mo-2.8Nb-0.2Si & - & $\beta$ \\
Ti-15Mo-5Zr-3Al & JIS T 7401-6 & $\beta$ \\
Ti-30Ta & - & $\beta$ \\
Ti-45Nb & AMS 4982 & $\beta$ \\
Ti-35Zr-10Nb & - & $\beta$ \\
Ti-35Nb-7Zr-5Ta & Task Force F-04.12.23 & $\beta$ \\
Ti-29Nb-13Ta-4.6Zr & - & $\beta$ \\
Ti-8Fe-8Ta & - & - \\
Ti-8Fe-8Ta-4Zr & - & $\beta$ \\
\hline
\end{tabular}

can be decreased by inhibiting the precipitation of the $\omega$ phase, whose Young's modulus is high due to the addition of V. The least value of Young's modulus reported thus far might be approximately $40 \mathrm{GPa}^{20)}$

Figure $1^{21)}$ shows the X-ray photographs of the healing states of experimental tibial fractures at 24 weeks after the implantation of intramedullary rods made of low modulus TNTZ, Ti-6Al-4V ELI or SUS 316L stainless steel. The posterior tibial bone becomes very thin at 24 weeks after the implantation of the intramedullary rods made of SUS 316L stainless steel. Therefore, the bone absorption occurred in the case of the SUS 316L intramedullary rod, but did not occur in the cases of the other two types of titanium alloys. Further, the remodeling is much better in the case of the TNTZ 


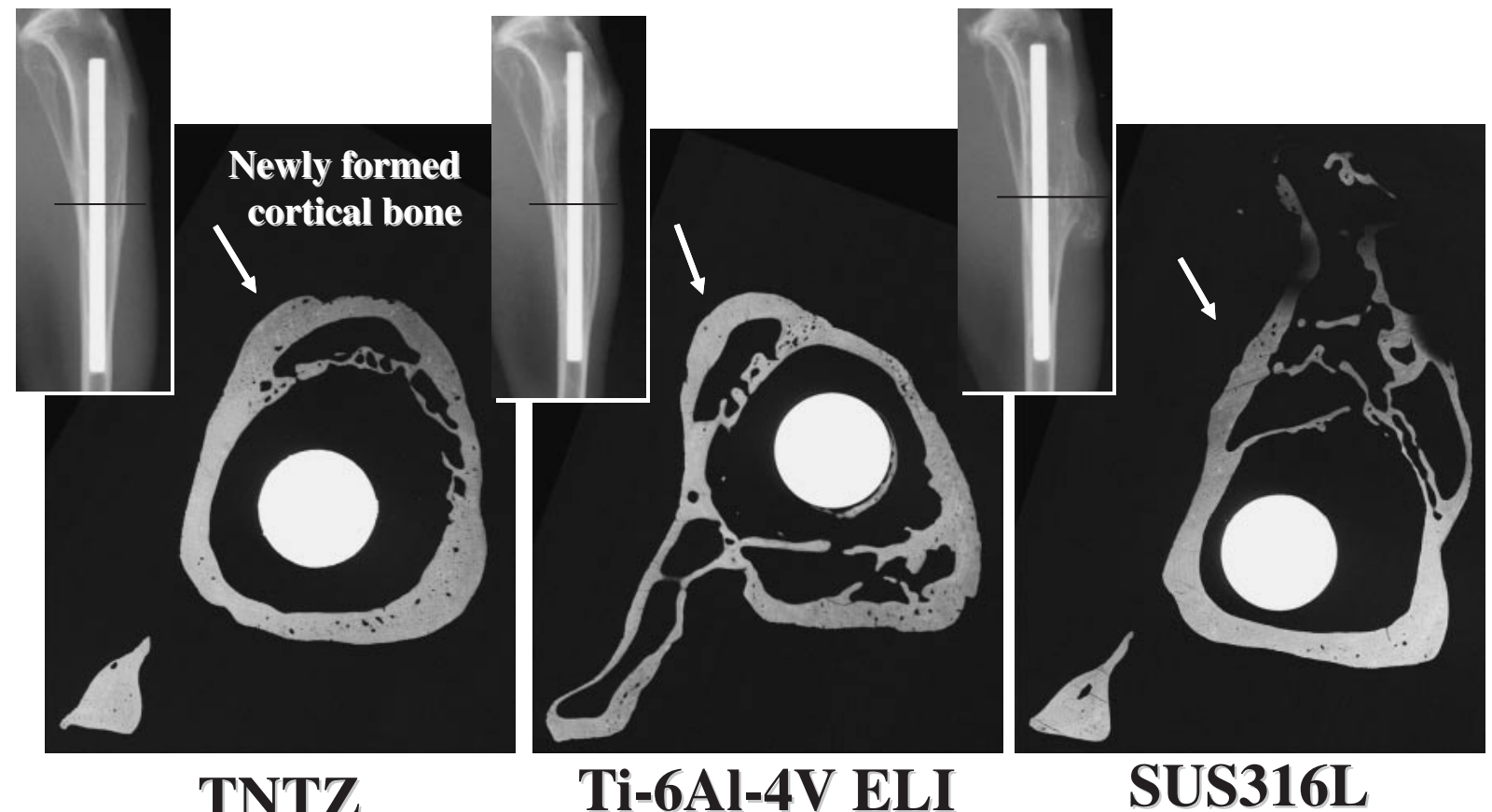

Fig. 2 CMR of cross section of tibia at 24 weeks after implantation.

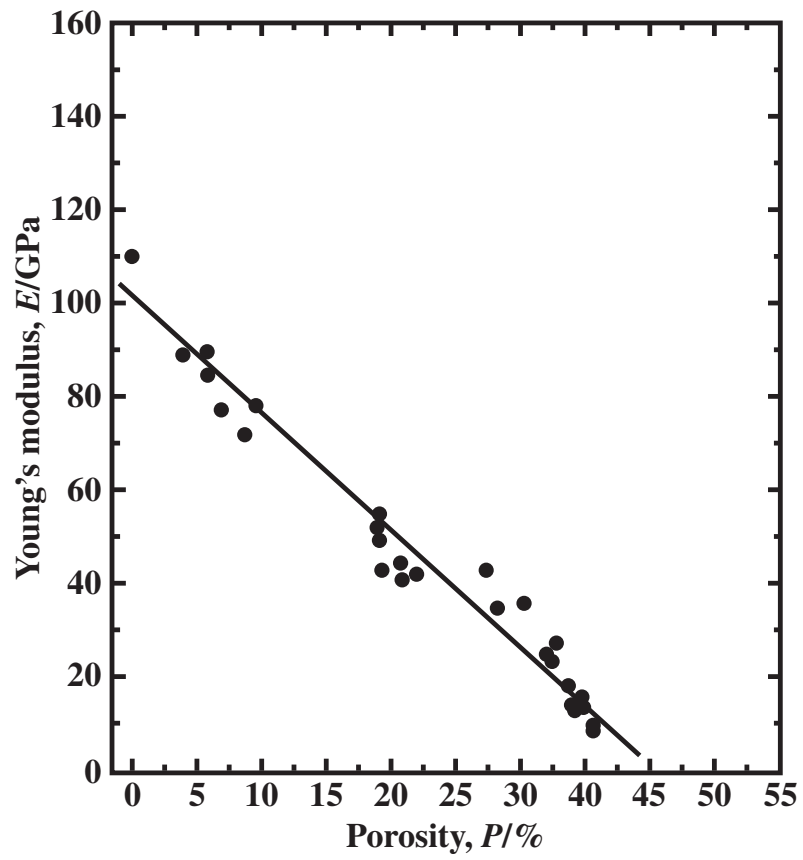

Fig. 3 Relationship between porosity and Young's modulus in porous titanium.

intramedullary rod than in the case of the Ti-6Al-4V ELI intramedullary one as shown in Fig. $2 .^{10)}$ These facts suggest an excellent stress transfer between the $\beta$-type titanium alloy with low Young's modulus and the bone.

In order to further reduce the Young's moduli of titanium and its alloys, it is very effective to make titanium and its alloys porous. The porous titanium is another way to reduce Young's modulus of titanium drastically. The Young's modulus can be easily controlled by changing the porosity.

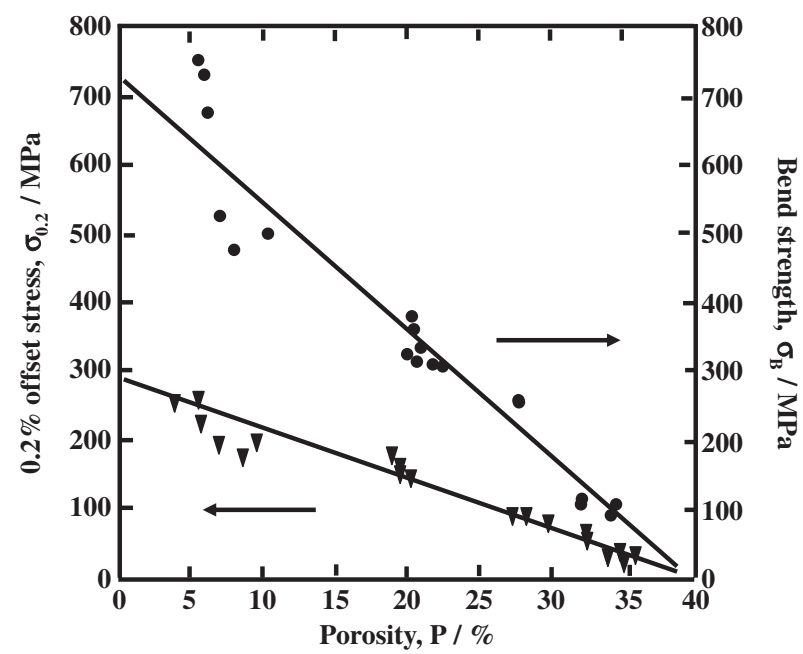

Fig. 4 Relationship between porosity and $0.2 \%$ proof stress or bend strength in porous titanium.

Figure $3^{22)}$ shows the relationship between Young's modulus and porosity of porous titanium made of titanium powder with different diameter in comparison with Young's modulus of bulk titanium. At a porosity of approximately $30 \%$, the Young's modulus is nearly equal to that of cortical bone. Using the titanium alloy with low Young's modulus, the Young's modulus can be equal to that of cortical bone at lower porosity in comparison with the case of titanium. The pores with the proper size also enhance the bone induction. On the other hand, its strength decreases drastically with increasing the porosity as shown in Fig. 4. ${ }^{22)}$ At a porosity of approximately $30 \%$, which leads to the Young's modulus equal to that of cortical bone, $0.2 \%$ proof stress is below $100 \mathrm{MPa}$. 


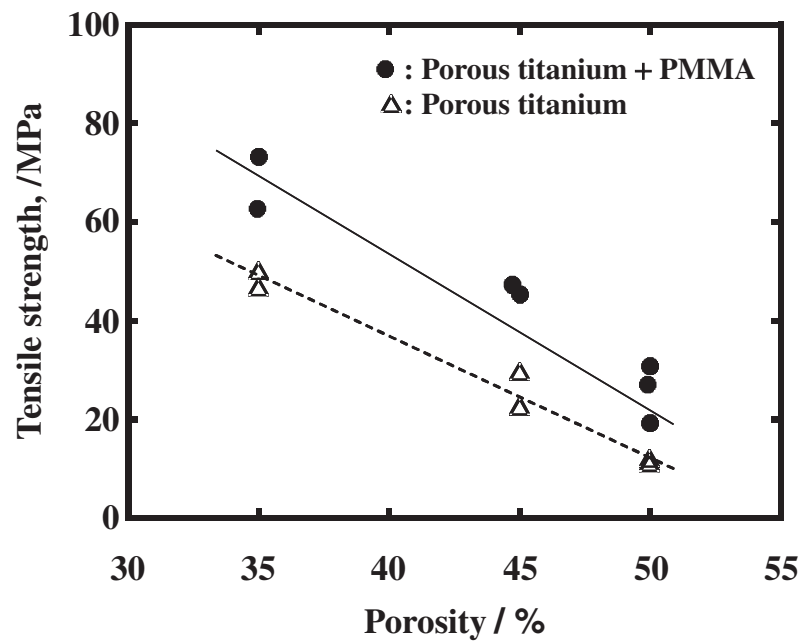

Fig. 5 Relationship between porosity and tensile strength in porous titanium and porous titanium-PMMA composites.

In order to inhibit decreasing strength of porous titanium, combining with biocompatible polymer is effective. One possible method to penetrate the polymer into the porous titanium is pressing. In this method, HMDP (high molecular density polyethylene) is pressed into porous titanium. ${ }^{23)}$

Another method proposed ${ }^{24)}$ is firstly using monomer of PMMA (polymethylmethacrylate); the porous titanium is firstly immersed into monomer of PMMA leading to penetrating monomer into porous titanium, and the monomer in porous titanium is subjected to polymerization by heating. Combining with PMMA, the strength of porous titanium increases as shown in Fig. $5 .^{24)}$ In this figure, the data of porous titanium and PMMA composites are plotted versus porosity in convenience although the composites do not contain pores. The strength of the composite is greater than that of porous titanium. Furthermore, bio-functionalities are considered to be easily added to porous titanium and polymer composites because the surface of porous titanium can be covered with polymer.

It is important to understand what level of Young's modulus is effective to inhibit the bone absorption when it is implanted.

\subsection{Multifunctional $\beta$-type titanium alloy composed of nontoxic and allergy-free elements}

Since functionalities such as superelasticity and shape memory effect are required in addition to a low Young's modulus, superelastic and/or shape memory $\beta$-type titanium alloys without toxic and allergic elements are developed.

As shown in Fig. 6, ${ }^{25)}$ after appropriate thermomechanical treatment, TNTZ stated above exhibits superelastic behavior, however, it does not exhibit shape memory effect. The superelastic behavior of this alloy cannot be explained by increasing the amount of deformation-induced martensite transformation and its reversion. The mechanism of this superelastic behavior is speculated that the elastic deformation progresses continuously in a different crystal direction although after lattice strain reaches maximum lattice strain where maximum lattice strain is the smallest because the maximum elastic strain is very different according to the

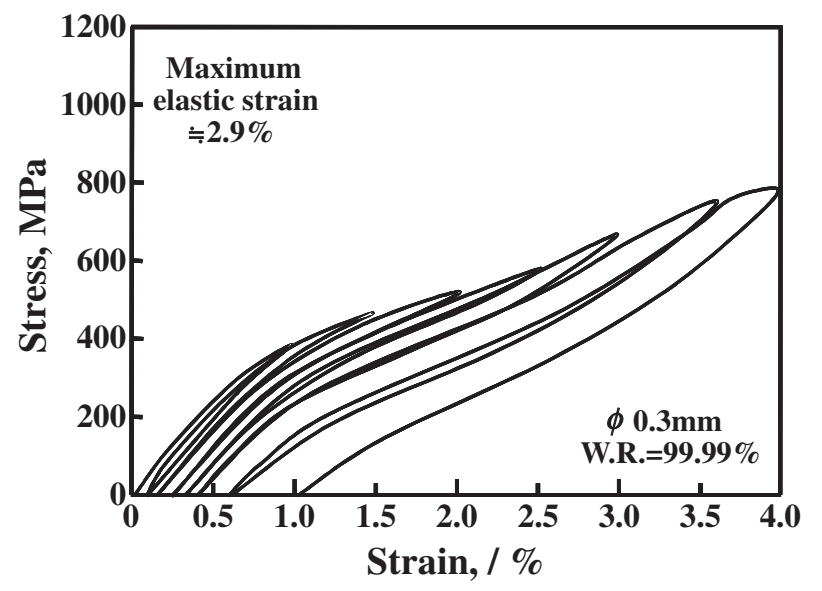

Fig. 6 Tensile loading-unloading curves of extruded wires of Ti-29Nb13Ta-4.6Zr with diameters of $0.3 \mathrm{~mm}$.

crystal direction. ${ }^{26)}$ However, the occurrence of the deformation induced-martensite transformation and its reverse transformation cannot be completely denied in this case. Further investigation is needed to make the mechanism of this superelastic behavior clear. The maximum elastic strain is approximately $3 \%$ after thermomechanical treatment. In the Ti-Nb-Ta-Zr system alloy, a change in the chemical composition can induce the shape memory effect. In this case, the shape memory effect is caused by the deformation induced-martensite transformation and its reverse transformation.

Ti-Nb-Sn system alloy, Ti-Mo-Ga system alloy, Ti-Nb-Al system alloy, Ti-Mo-Al system alloy, Ti-Ta system alloy, Ti$\mathrm{Nb}$ system alloy, Ti-Sc-Mo system alloy, Ti-Mo-Ag system alloy, Ti-Mo-Sn system alloy, Ti-Nb-Ta-Zr system alloy, etc., have been developed. ${ }^{10)}$ Shape memory $\beta$-type titanium alloys exhibit superelastic behaviors because they exhibit pseudo-elastic behavior. Among these alloys, approximately $6 \%$ elastic strain was reportedly obtained in one of the Ti-NbAl system alloys by controlling its texture. ${ }^{27)}$ The shape memory effect of these alloys is associated with the deformation-induced martensite transformation and its reverse transformation.

The Ni-free superelastic and/or shape memory $\beta$-type titanium alloys are expected to be used in stents, guide wires of catheters, orthodontic wires, etc.

\section{Fatigue Behavior and Aging}

In general, the fatigue strength of titanium alloys is improved by aging after ST. The fatigue strength is drastically improved by aging treatment after ST for $\beta$-type titanium alloys. Figure $7^{28}$ ) shows the S-N curves obtained from fatigue tests in air on TNTZ samples subjected to ST at $1023 \mathrm{~K}\left(A_{\mathrm{ST}}\right)$ and aging treatments at $723 \mathrm{~K}$ for various durations after ST - under-aging $\left(U A_{723 \mathrm{~K}}\right)$, peak-aging $\left(P A_{723 \mathrm{~K}}\right)$, and over-aging $\left(O A_{723 \mathrm{~K}}\right)$ obtained from fatigue tests in air. The fatigue limit of TNTZ increases drastically by aging treatments, and the fatigue limit of peak-aged TNTZ is the highest. The fatigue limits of each aged TNTZ samples are equivalent to that of Ti-6Al-4V ELI. 


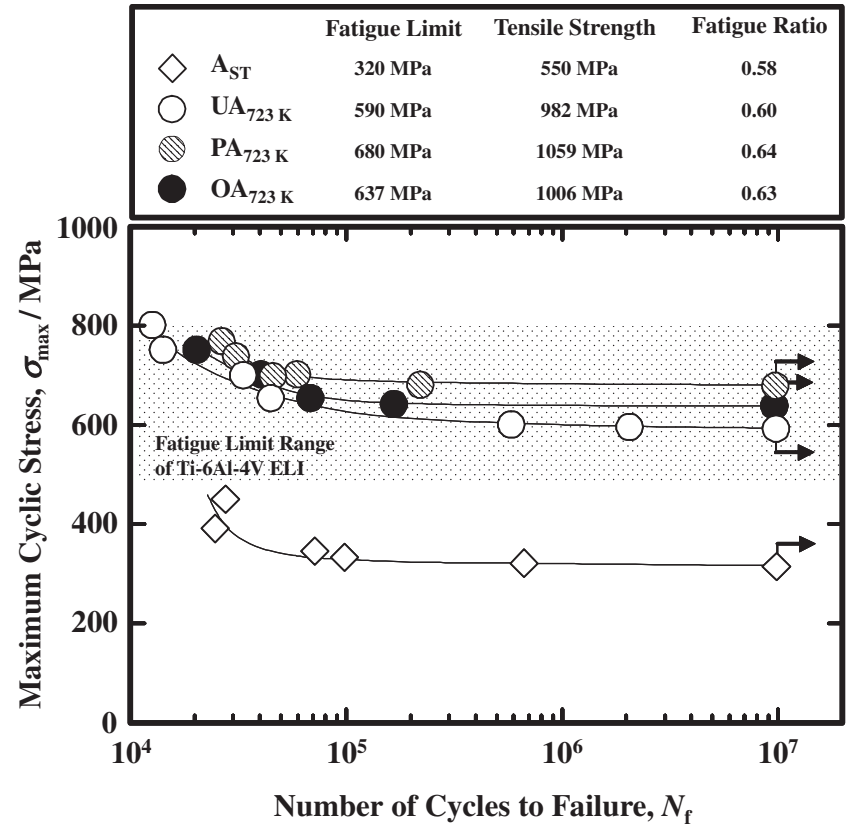

Fig. 7 S-N curves of $A_{\mathrm{ST}}, U A_{723 \mathrm{~K}}, P A_{723 \mathrm{~K}}$, and $O A_{723 \mathrm{~K}}$ obtained from fatigue tests in air.

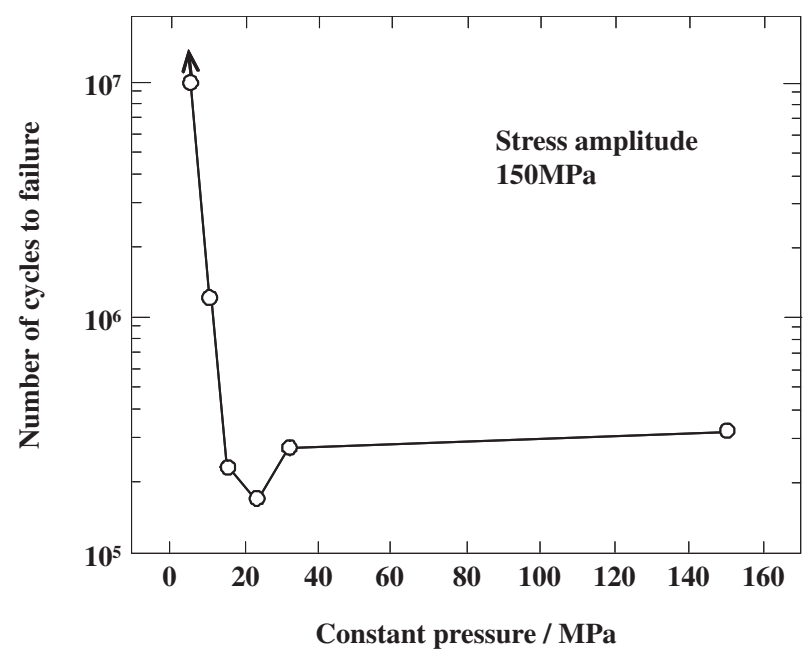

Fig. 8 Relationship between constant pressure and the number of cycles to failure in Ti-6Al-4V.

\section{Fretting Fatigue}

When the fretting and fatigue occur simultaneously, the fatigue strength of biomedical titanium alloys decreases significantly. Such situations may occur in the cases such as bone plate and screw, and hip joint stem and bone, where two bodies remain in contact with each other under cyclic loading conditions. This is called fretting fatigue.

The fretting fatigue strengths of biomedical titanium alloys are affected by various factors such as contact pressure, stress amplitude, relative slip distance, friction coefficient, mean stress, frequency, contact conditions, material quality, and circumstance. As an example of the effects of these factors on the fretting fatigue of biomedical titanium alloys, the effect of contact pressure on the number of the cycles before failure for Ti-6Al-4V is shown in Fig. $8,{ }^{29)}$ based on the results

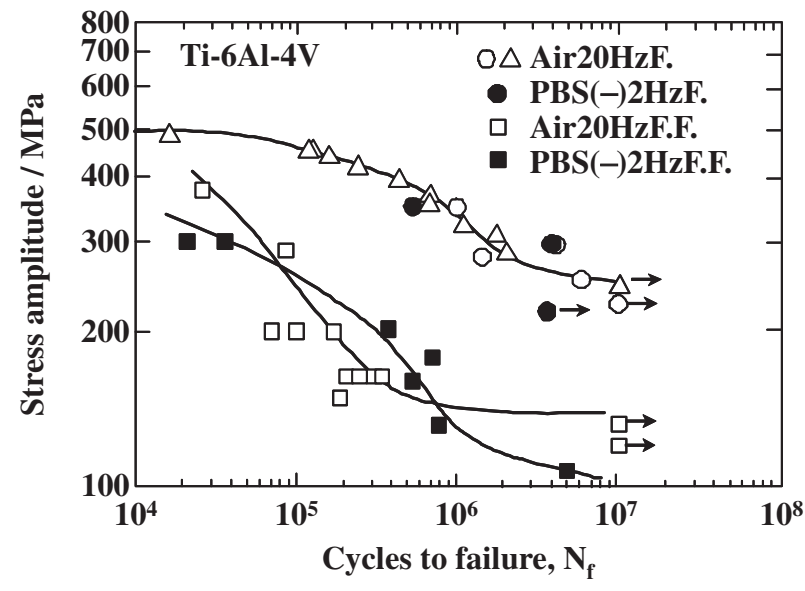

Fig. 9 Cycles to failure as a function of stress amplitude (F: Fatigure, F.F.: Fretting fatigure, $\triangle$ : another Ti-6Al-4V alloy data).

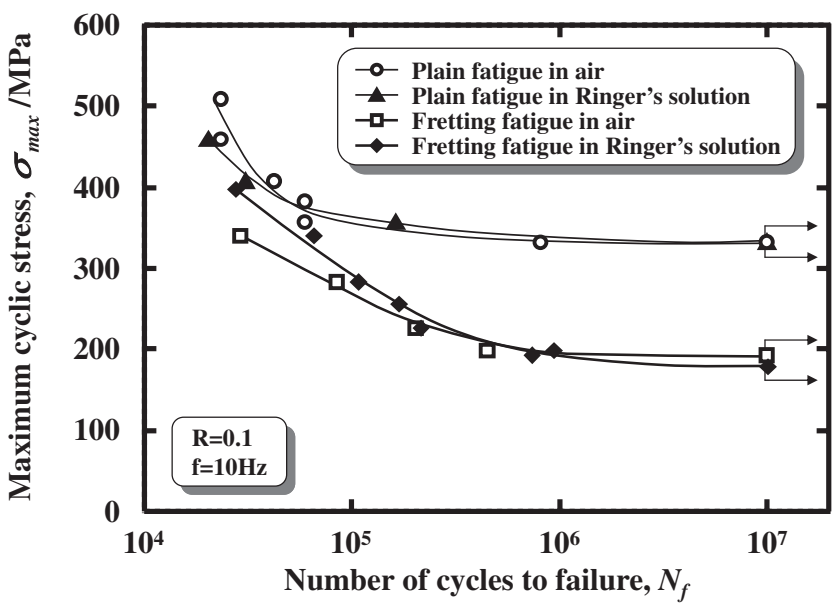

Fig. 10 S-N curves of TNTZ obtained from plain fatigue and fretting fatigue tests in air and Ringer's solution.

obtained from fretting fatigue tests. At a contact pressure of approximately $20 \mathrm{MPa}$, Ti-6Al-4V exhibits the least fretting fatigue life. This trend has also been reported for the other titanium alloys such as Ti-4.5Al-3V-2Mo-2Fe (SP-700), ${ }^{30)}$ which may also be applicable in the biomedical field. ${ }^{31)}$ In the case of steels, the fretting fatigue life decreases with increasing contact pressure.

Figure $9^{32)}$ shows the plain fatigue and fretting fatigue strength of Ti-6Al-4V in air and in a simulated body fluid (PBS (-)). As stated above, the fretting fatigue strength of Ti-6Al-4V is significantly smaller in comparison with its plain fatigue strength in both air and PBS (-). The plain fatigue strength of Ti-6Al-4V is nearly the same in air and PBS (-). On the other hand, the fretting fatigue strength of Ti-6Al-4V is less in PBS (-) in the low- and high-cycle fatigue life regions, but in the medium-cycle fatigue life region, it is greater in PBS (-) than in air. As shown in Fig. $10,{ }^{33)}$ in the case of TNTZ, the trend in the fretting fatigue strength in air and in a simulated body fluid (Ringer's solution) in the low cycle fatigue life region is different from that of Ti-6Al-4V, as stated above; the fretting fatigue strength is greater in Ringer's solution than in air. This is 


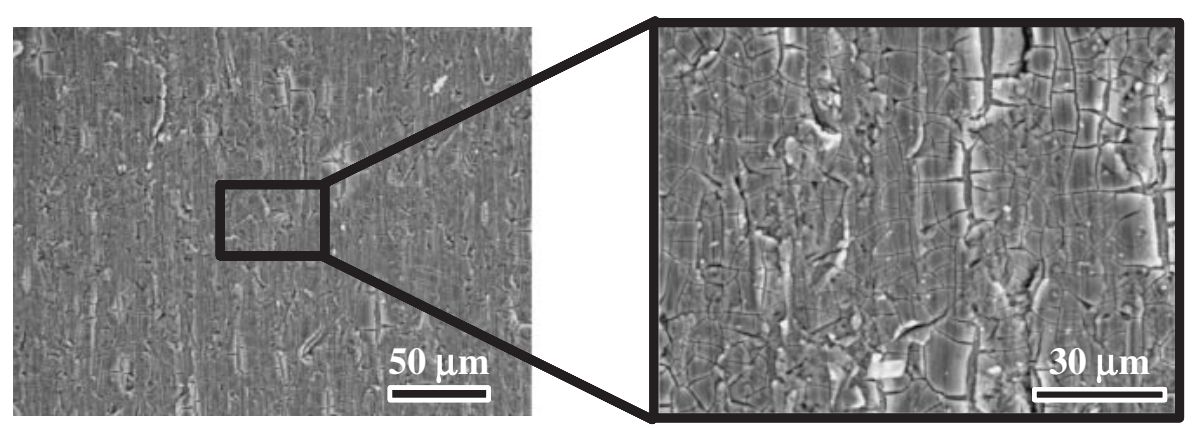

(a) TNTZ

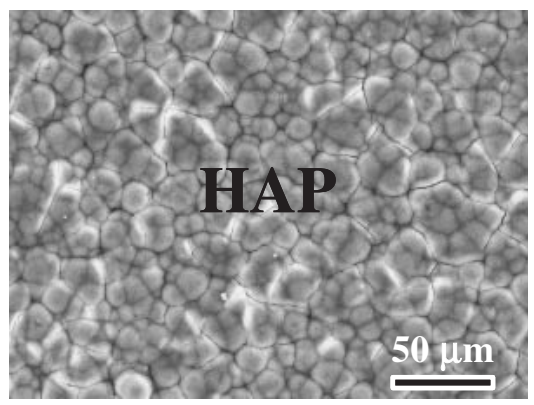

(b) CP-Ti

Fig. 11 SEM micrographs of specimen surfaces of (a) TNTZ and (b) CP-Ti dipped in SBF for $604.8 \mathrm{ks}$ (1 week) after NaOH treatment followed by baking.

explained as being the result of the significantly higher lubrication effect caused by the Ringer's solution.

\section{Bioactive Ceramic Surface Modification}

Titanium alloys exhibit the highest biocompatibility among metallic materials for biomedical applications. However, as stated above, they are classified as bioinert materials as well as ceramics such as alumina and zirconia on the basis of the pattern of osteogensis. ${ }^{11)}$ Further their biocompatibility is inferior to that of phosphate calcium $(\mathrm{CaP})$ or hydroxyapatite (HAP: $\left.\mathrm{Ca}\left(\mathrm{PO}_{4}\right)_{3} \mathrm{OH}\right)$, which is classified as a bioactive material. Therefore, bioactive surface treatment (bioactive surface modification) is, in general, applied to titanium alloys for biomedical applications in order to further improve their biocompatibility. For this treatment, phosphate-calcium-type ceramics such as phosphate calcium $(\mathrm{CaP})$, TCP $\left(\beta-\mathrm{Ca}_{3}\left(\mathrm{PO}_{4}\right)_{2}\right)$, and $\mathrm{CCP}\left(\beta-\mathrm{Ca}_{2} \mathrm{P}_{2} \mathrm{O}_{7}\right)$ and $\mathrm{HAP}$ are mainly coated on the surface of the titanium alloy. In general, the final aim of the treatment process is the formation of HAP.

The bioactive surface treatment processes are, in general, classified as dry processes and wet processes. There are various dry and wet processes. ${ }^{7)}$

The dry processes are further classified as direct HAP forming methods and indirect HAP forming methods. The examples of the former methods are the plasma spray method, ion plating, RF magnetron sputtering, pulse laser deposition method, ion-beam dynamic mixing method, super plastic joining method, etc., where HAP is formed directly on the titanium alloy surface. Examples of the latter methods are calcium ion implantation, in which calcium ions are implanted into biomedical titanium alloys; the calcium ion mixing method, in which $\mathrm{Ca}$ is sputtered on the surface of biomedical titanium alloys followed by $\mathrm{Ar}$ ion implantation; etc. When biomedical titanium alloys subjected to these treatments are implanted into a living body, $\mathrm{CaP}$ precipitation is enhanced on the surface.

Wet processes are, for example, electrical chemical treatment, in which the biomedical titanium is first subjected to anodic treatment followed by cathodic treatment in $\left(\mathrm{Ca}\left(\mathrm{NO}_{3}\right)_{2}\right)$ solution, following which, it is immersed into living body liquid, and alkali treatment, in which the biomedical titanium alloy is first immersed into $\mathrm{NaOH}$ solution and heated, following which, it is immersed into living body liquid. The formability of HAP by these treatments is sensitive to the chemical compositions of the titanium alloys. Figure $11^{34)}$ shows SEM micrographs of specimen surfaces of (a) TNTZ and (b) pure titanium (CP-Ti) dipped into SBF for $604.8 \mathrm{ks}$ (1week) after $\mathrm{NaOH}$ treatment followed by baking. The whole surface of CP-Ti is covered with HAP, while the HAP is not formed on the surface of TNTZ. The formability of HAP is much lower in TNTZ than in CP-Ti. TNTZ contains a large amount of $\mathrm{Nb}$ and $\mathrm{Ta}$, and small amount of $\mathrm{Zr}$. Therefore, which element is strongly inhibits the formation of HAP should be made clear.

Figure 12 shows SEM micrographs of specimen surfaces of Ti-30Nb, Ti-10Ta and Ti-5Zr dipped in SBF for 1 week after dipping into $5 \mathrm{M} \mathrm{NaOH}$ solution for $172.8 \mathrm{ks}$ ( 2 days). The formability of HAP is much lower in Ti-30Nb than in Ti-10Ta and Ti-5Zr. In the case of Ti-30Nb, $\mathrm{Na}_{2} \mathrm{Ti}_{5} \mathrm{O}_{11}$. $\mathrm{H}_{2} \mathrm{O}$ and $\mathrm{NaNbO}_{3} \cdot \mathrm{H}_{2} \mathrm{O}$ are formed on the surface after immersed into $\mathrm{NaOH}$ solution, while only $\mathrm{Na}_{2} \mathrm{Ti}_{5} \mathrm{O}_{11}$ is formed on the surfaces of Ti-10Ta and Ti-5Zr. $\mathrm{NaNbO}_{3}$. $\mathrm{H}_{2} \mathrm{O}$ might inhibit the formation of HAP on the surface of TNTZ. 
(a) $\mathrm{Ti}-30 \mathrm{Nb}$

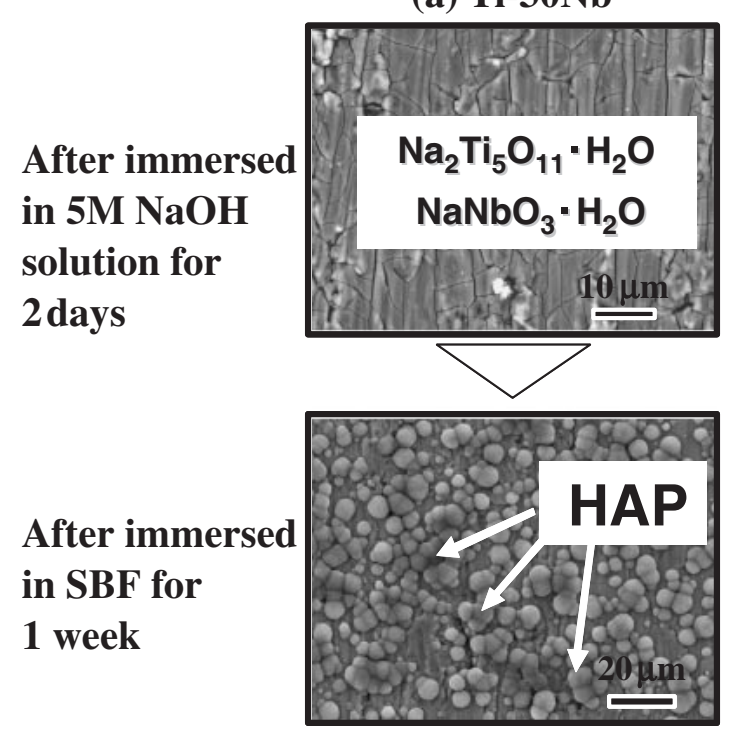

(b) Ti-10Ta
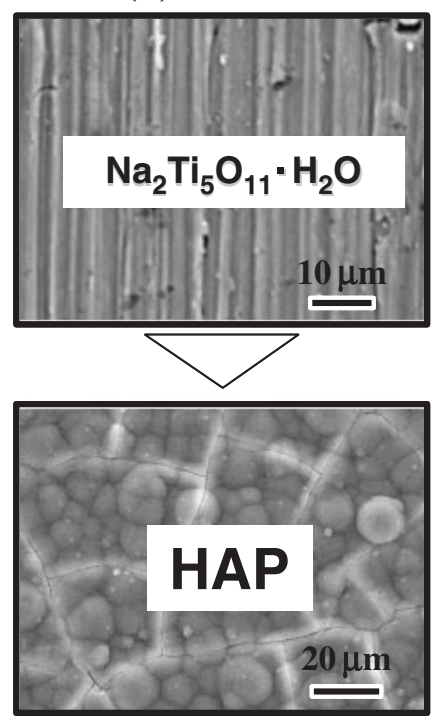

(c) $\mathrm{Ti}-5 \mathrm{Zr}$
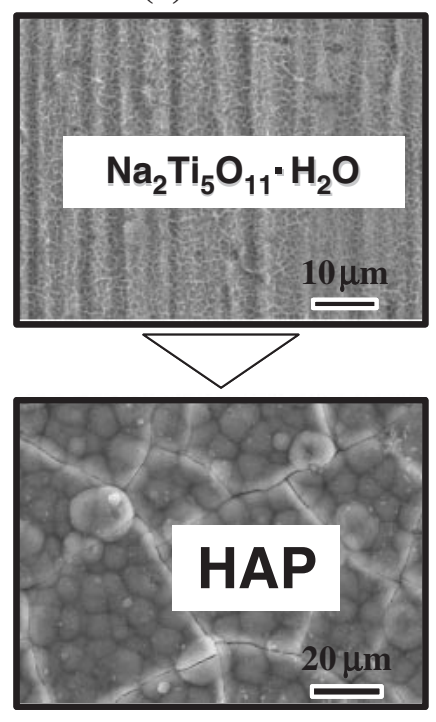

Fig. 12 SEM micrographs of specimen surfaces of (a) Ti-30Nb, (b) Ti-10Ta, and (c) Ti-5Zr dipped in SBF for $604.8 \mathrm{ks}$ (1 week) after dipping in $5 \mathrm{M} \mathrm{NaOH}$ solution for $172.8 \mathrm{ks}$ (2 days).

Table 2 Formability of HAP on specimen surfaces of CP-Ti, CP-Nb, CP-Ta and CP-Zr as functions of alkali treatment conditions and immersion time in SBF.

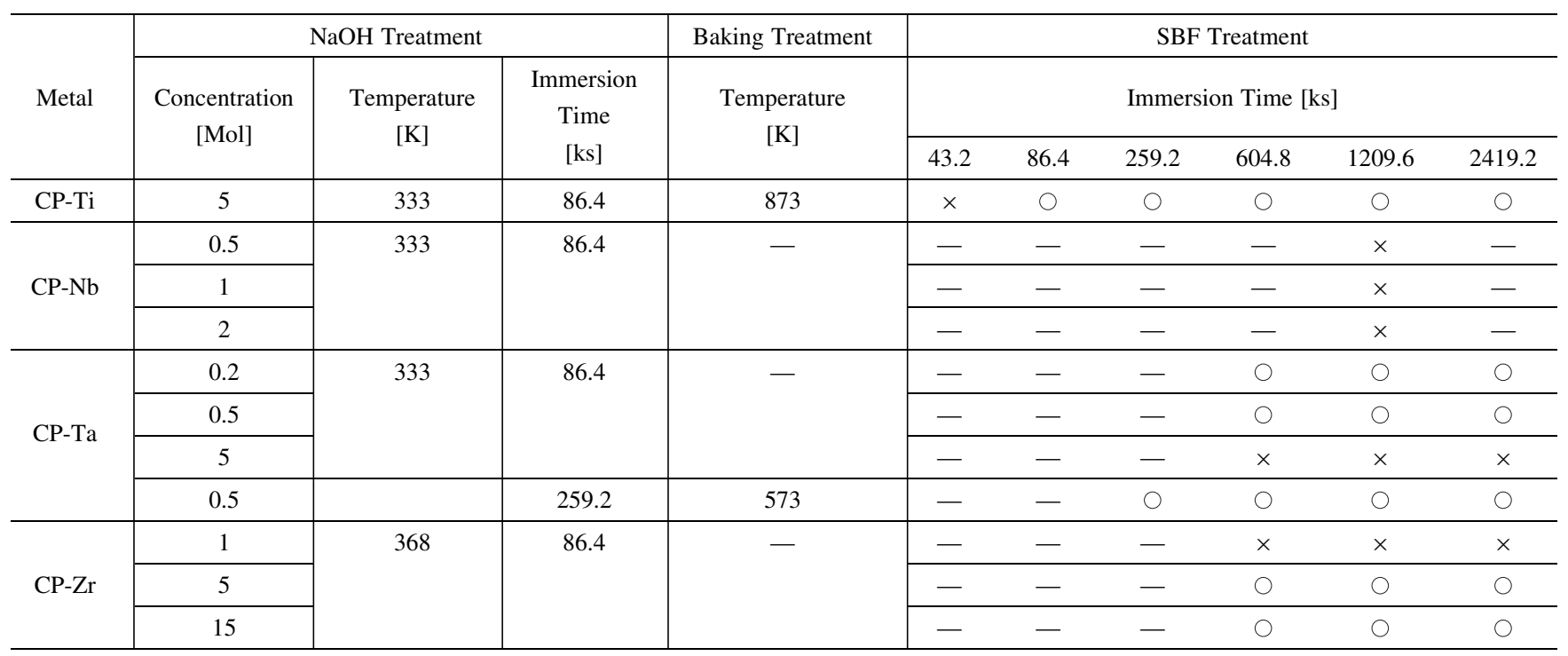

$\bigcirc$ : Specimen surface was covered with HAP. $x$ : HAP was not formed on specimen surface.

There is another report ${ }^{34)}$ that the formability of HAP is less in pure $\mathrm{Nb}(\mathrm{CP}-\mathrm{Nb})$ than in pure $\mathrm{Ta}(\mathrm{CP}-\mathrm{Ta})$ and pure $\mathrm{Zr}(\mathrm{CP}-\mathrm{Zr})$ as summarized in Table 2. The formability of $\mathrm{HAP}$ is the lowest in $\mathrm{CP}-\mathrm{Nb}$.

Another interesting treatment method ${ }^{35)}$ (Fig. 13) is the dip-coating method, in which calcium phosphate invert glass powder mixed with distilled water is coated on the surface of the titanium alloy; this is followed by heating at around $1073 \mathrm{~K}$ (firing), after which the phosphate-calcium-type ceramics precipitate. By this process, bioactive $\beta$-TCP and $\beta$-CCP are formed on the surface of TNTZ. This treatment is more advantageous for oxidation resistant titanium alloys such as TNTZ.

Furthermore, HAP is formed by immersing calciumphosphate invert glass-ceramic coated titanium alloys in simulated body fluid (SBF). The apatite formation by soaking in SBF is enhanced by autoclaving.

\section{Polymer Surface Modification}

If tight polymer modification is performed on the surface of titanium alloys, it might impart high-order biofunctionality, thereby yielding the base materials for artificial organs. The coating of polymers such as MPC polymer, which is a blood compatible polymer, on titanium alloys has been practically achieved. ${ }^{36)}$ However, the polymer surface modification of titanium alloys through chemical bonding is in greater demand. Recently, an electric deposition method, by which PEG (polyethylene glycol), which inhibits the adhesion of protein on the surface of titanium alloys, can be 


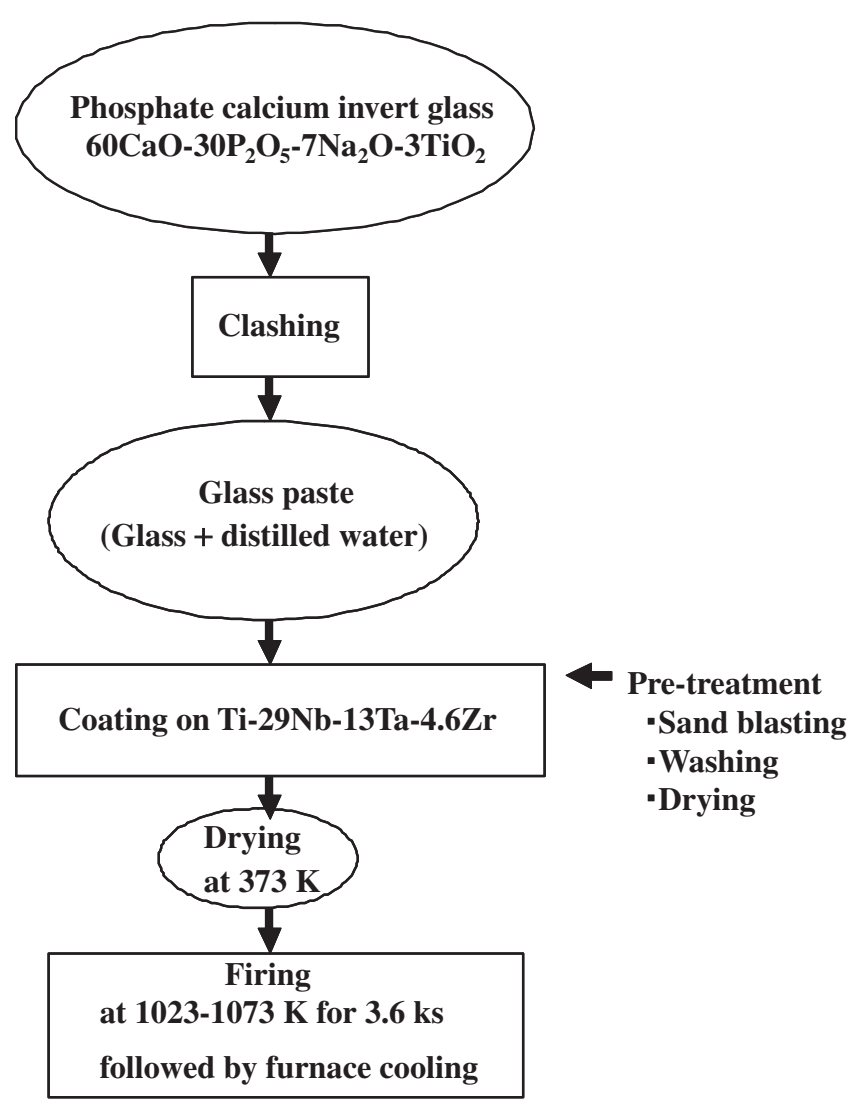

Fig. 13 Schematic explanation of coating of phosphate calcium crystallized glass on TNTZ.

modified on the surface of titanium alloys through chemical bonding, has been proposed. ${ }^{37)}$ In this method, an electric current is passed through a mixed solution of PEG, in which a titanium plate serves as the cathode and a platinum plate as the anode; one or both of the PEG terminals are modified by $\mathrm{NH}_{2}$ and $\mathrm{NaCl}$. PEG bonds to the surface of the titanium plate through ion bonding along random directions by immersion. By electric deposition, however, PEG bonds tightly to the surface of the titanium plate, where both its terminals are aligned along the direction of the plate through $\mathrm{NH}-\mathrm{O}$ bonding. PEG bonds according to a U-like shape when both its terminals are modified; however, it bonds a brush-like shape when only one terminal is modified, as shown schematically in Fig. 14. ${ }^{37)}$ The chemical bonding of PEG to the surface of the abovementioned titanium plate might strongly depend on the titanium oxide formed on the surface of the titanium plate. The polymer surface modification of the titanium alloys through chemical bonding by using a method such as that states above will be important in the near future.

\section{Summary}

The application of titanium and its alloys in biomedical applications is rapidly increasing. Therefore, further developments of titanium alloys appropriate for biomedical applications are strongly desired. For these applications, titanium alloys that comprise nontoxic and allergy-free elements should be developed. Further, these alloys should exhibit functionalities such as superelasticity and shape

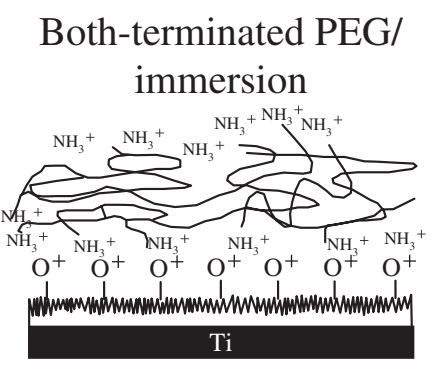

\section{One-terminated PEG/ Electrodeposition}

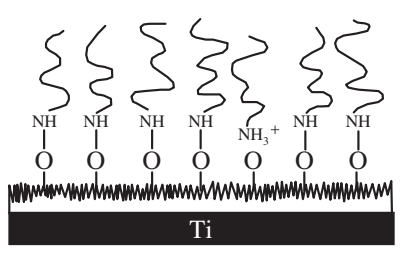

Both-terminated
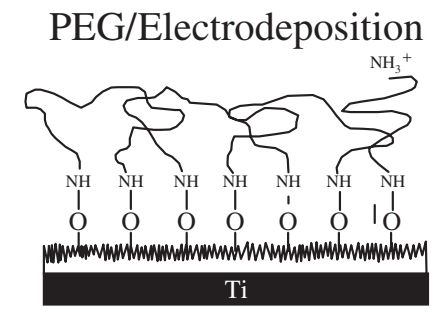

Fig. 14 Schematic model of deposition mode and chemical bonding state of PEG by immersion and electrodeposition.

memory effect. In addition, mechanical performance parameters such as strength, ductility, fatigue strength, fretting fatigue strength, and wear resistance are very important factors for biomedical applications.

\section{REFERENCES}

1) D. Kuroda, M. Niinomi, M. Morinaga, Y. Kato and T. Yashiro: Mat. Sci. Eng. A A243 (1998) 244-249.

2) M. Niinomi: Materia Japan. 37 (1998) pp. 843-846.

3) T. Ahmed, M. Lomg, J. Silvestri, C. Ruiz and H. J. Rack: Titanium'95, eds. P. A. Blenkinsop, W. J. Evans and H. M. Flower (The Inst. Materials 1996) p. 1760.

4) M. Niinomi: Met. Mat. Trans A 32A (2001) 477-486.

5) M. Niinomi, T. Hattori, K. Morikawa, T. Kasuga, A. Suzuki, H. Fukui and S. Niwa: Mater. Trans. 43 (2002) 2970-2877.

6) M. Niinomi: Biomaterials 24 (2003) 2673-2683.

7) M. Niinomi: STAM 4 (2003) 445-454

8) M. Niinomi, T. Akahori, K. Morikawa, T. Kasuga, H. Fuki, A. Suzuki, K. Kyo and S. Niwa: ASTM STP 1471 (2006) pp. 135-150.

9) S. Saito et al.: Science 300 (2003) 464-467.

10) M. Niinomi, T. Hanawa and T. Narushima: JOM 57 (2005) 18-24.

11) T. Yamamuro: J. Japan Soc. Biomaterials 7 (1989) 19-23.

12) T. Hanawa, H. Sakamoto, Y. Iwasaki, Y. Tanaka and H. Imai: Proc. Meeting of Materials Research Federation of Science Council Japan, (2005) pp. 343-344.

13) T. Hattori, K. Morikawa, S. Niwa, M. Niinomi and A. Suzuki: Proc. Int. Conf. on Biomechanics combined with the Annual Scientific Meeting of Taiwanese Society of Biomechanics, (2001) p. 28.

14) Y. Okazaki, S. Asao, S. Rao and T. Tateishi: J. Japan Inst. Metals. 60 (1996) 902-906.

15) A. Yamamoto, T. Kobayashi, N. Maruyama, K. Nakazawa and M. Sumita: J. Japan Inst. Metals 59 (1995) 463-470.

16) M. Niinomi: Int. J. Fatigue 29 (2007) 992-1000.

17) M. Niinomi: J. Mechanical Behavior of Biomedical Materials 1 (2008) $30-42$.

18) Y. Okazaki, S. Rao, T. Tateishi and Y. Ito: Mat. Sci. Eng. A, A243 (1998) 250.

19) M. Niinomi, T. Hattori and S. Niwa: Biomaterials in Orthopedics, eds. M. J. Yaszemski, D. J. Trantolo, K. U. Lewandrowski, V. Hasirci, D. E. Altobelli and D. L. Wise, (Marcel Dekker, INC, 2004) pp. 41-62.

20) H. Matsumoto, S. Watanabe and S. Hanada: Medical Device Materials 
III, eds. R. Venugopalan and M. Wu, (2006) pp. 9-14.

21) T. Hattori, K. Morikawa, S. Niwa, K. Sato, M. Niinomi and A. Suzuki: Proc. Int. Conf. on biomechanics combined with the Annual Scientific Meeting of Taiwanese Society of Biomechanics, (2001) p. 28.

22) I. H. Oh, N. Nomura, N. Masahashi and S. Hanada: Scr. Mater. 49 (2003) 1197-1202.

23) Y. Baba, N. Nomura, S. Fujinuma, J. Kawamura, M. Chiba, N. Masahashi and S. Hanada: Abstracts of the 137th Fall Meeting of JIM (2005) p. 441.

24) M. Nakai, M. Niinomi, T. Akahori, Y. Shinozaki, H. Toda, S. Itsuno, N. Haraguchi, Y. Itoh, T. Ogasawara and T. Onishi: Abstract s of the 28th Annual Meeting of Japanese Society for Biomaterials (2006) p. 350.

25) M. Niinomi, T. Akahori, S. Katsura, K. Yamauchi and M. Ogawa: Mater. Sci. Eng. C 27 (2007) 154-161.

26) M. Niinomi, T. Akahori and M. Nakai: Mater. Sci. Eng. C 28 (2008) 406-413.

27) H. Hosoda and S. Miyazaki: J. Jpn. Soc. Mech. Eng. 107 (2004) 509-520.

28) T. Akahori, M. Niinomi, A. Noda, H. Toda, H. Fukui and M. Ogawa:
J. Jpn. Inst. of Metals 70 (2006) 295-303.

29) M. Sumita, K. Nakazawa, N. Maruyama, Y. Kawabe, T. Nishijima, T. Fujii and K. Saito: Research Reports of National Institute for Materials Science 14 (1993) 207-218.

30) J. Takeda, M. Niinomi, T. Akahori and Y. Suzuki and H. Toda: J. Jpn. Inst. Light Met. 55 (2005) 661-667.

31) Gunawarman, M. Niinomi, T. Akahori, T. Souma, M. Ikeda, H. Toda and K. Terashima: Mater. Trans. 46 (2005) 1570-1777.

32) N. Maruyama, T. Kobayashi and M. Sumita: J. J. Soc. Biomat. 13 (1995) 14-20.

33) M. Niinomii, T. Akahori, T. Yabunaka, H. Fukui and A. Suzuki: J. Iron Steel Instit. Jpn. 88 (2002) 553-560.

34) T. Akahori, M. Niinomi, M. Nakai, H. Fukuda, H. Fukui and M. Ogawa: Mater. Trans. 48 (2007), to be published.

35) Y. Hirobe, T. Kasuga, M. Nogami and M. Niinomi: Phosphorus Research Bulletin 17 (2004) 258-261.

36) K. Ishihara and T. Yoneyama: Materia Japan 43 (2004) 118-121.

37) Y. Tanaka, H. Doi, Y. Iwasaki, S. Hiromoto, T. Yoneyama, K. Asami, H. Imai and T. Hanawa: Mater. Sci. Eng. C (2006). 